Proceedings

\title{
Anti-SARS-CoV-2 Antibodies Frequency in Non-Health Care Workers in a Highly Industrialized Province of Northern Italy ${ }^{\dagger}$
}

\author{
Alberto Modenese ${ }^{1, *}$, Tommaso Mazzoli ${ }^{2}$, Nausicaa Berselli ${ }^{1}$, Davide Ferrari ${ }^{2}$, Annalisa Bargellini ${ }^{1}$, Paola Borella ${ }^{1}$, \\ Tommaso Filippini ${ }^{1}$, Isabella Marchesi ${ }^{1}$, Stefania Paduano ${ }^{1}$, Marco Vinceti ${ }^{1}$ and Fabriziomaria Gobba ${ }^{1}$ \\ 1 Department of Biomedical, Metabolic and Neural Sciences, University of Modena and Reggio Emilia, Mo- \\ dena, Italy; alberto.modenese@unimore.it \\ 2 Department of Public Health, National Health Service, Modena, Italy; da.ferrari@ausl.mo.it \\ * Correspondence: alberto.modenese@unimore.it (A.M.)
}

Publisher's Note: MDPI stays neutral with regard to jurisdictional claims in published maps and institutional affiliations.

\section{(c) (i)}

Copyright: $(\odot 2021$ by the authors. Submitted for possible open access publication under the terms and conditions of the Creative Commons Attribution (CC BY) license (http://creativecommons.org/licenses /by/4.0/).

\begin{abstract}
We estimated the frequency of anti-SARS-Cov-2 antibodies in non-Health Care Workers (non-HCW) of the highly industrialized province of Modena, northern Italy. Samples were collected during a voluntarily screening campaign provided by several companies of this territory from 18th May to 5th October 2020. Antibodies were found in 1103 workers, $0.45 \%$ of the total number of non-HCWs in Modena province (about 246.000). The positive workers were mainly engaged in manufacture $(60 \%)$, trade sector $(12 \%)$, transport $(9 \%)$, scientific and technical activities $(5 \%)$, arts, sports and recreation activities (4.5\%). In data evaluation, lockdown-related closing of several potentially at risk activities deserves consideration.
\end{abstract}

Keywords: SARS-CoV2; Covid-19; SARS-CoV2 antibody; occupational exposure; occupational health; work-related risk

\section{Introduction}

During the first wave of the SARS-CoV-2 pandemic in Italy, highly industrialized northern regions of the Country were most heavily involved. One of these regions is Emilia-Romagna, where it is located the province of Modena, one of the most densely populated and industrialized areas of Italy, with a high number of active workers. In this area the proportion of the workers engaged in industrial activities is higher compare to the average proportion in Italy, being about the $40 \%$ compared to a national data of the $30 \%$ [1]. A parameter commonly applied to study the epidemiology of SARS-CoV-2 infection, that can be applied also in working populations, is the frequency of serum specific antibodies. While numerous data have been published up today on the prevalence of the infection in healthcare workers (HCW) [2], there is still a scarcity of data on the diffusion of the new coronavirus in other work activities [3]. Nevertheless, even if few reports have been published on this topic, some working conditions, as meat processing or transportation, have been considered at risk of infection. In Italy, a body of data on the infection rate in specific categories of workers is available only for HCW, for whom it is currently estimated a total number of more than 90000 cases [4], and a prevalence of the $12.2 \%$ [5]. Recent data of the National Institute for Insurance against Accidents at Work (INAIL) indicate that, among all the applications for COVID-19 compensations, about thirty-thousands in total, the $71.6 \%$, came from Human health and social work activities, the $10.4 \%$ from the Public administration and defense activities, the $4.1 \%$ from the Administrative and support service activities, the $2.6 \%$ from the Manufacturing sector, the $2.4 \%$ from the Accommodation and food service activities, the $2.1 \%$ from the Agriculture, forestry and fishing sector and only the $6.8 \%$ from all the other occupational activities [5]. According to the European Centre for Disease Prevention and Control (ECDC), out- 
breaks and clusters of COVID-19 have been reported for a variety of occupational settings, with more than 1300 clusters up to July 2020 [6]. Among the activities potentially involving a higher risk for workers, there are those involving close physical proximity of the workers, in particular when the activities are conducted in indoor settings or with shared transport or accommodation [6]. Several clusters have been reported from the food packaging and processing sectors, with indications of possible outbreaks in particular in workers of meat and poultry processing factories [7], as well as in other factories and manufacturing activities and in office settings [6]. The aim of this work is to present a panorama of the frequency of anti-SARS-CoV-2 antibodies positivity in non-healthcare workers employed in the highly industrialized province of Modena, northern Italy.

\section{Materials and Methods}

We collected all the cases of SARS-Cov-2 antibodies positivity resulting from serological tests within a specific voluntarily screening campaign performed in several companies of the province of Modena in the period between the $18^{\text {th }}$ May and the $5^{\text {th }}$ October 2020. The access to the total number of cases was possible based on the compulsory notifications of all antibodies positivity in workers, received by the Section of Occupational Health and Safety of the local Department of Public Health: all cases of anti-SARS-CoV-2 positivity, either IgM or IgG positivity, or positivity of both the classes of immunoglobulins, had to be notified based on a regional disposal, and all the positive workers needed to undergo a diagnostic RT-PCR nasopharyngeal swab to exclude or confirm an ongoing infection. The notifications could be made by the general practitioners or directly by the occupational physicians of the companies involved in the screening, with the support of the labs that performed the tests. In the former cases, no detailed information on the occupational sectors and types of activity performed by the workers could be retrieved, while in the latter cases this information was available together with the notification form of the positivity. For different reasons, not all the occupational sectors are included in our notifications registry. Healthcare workers are not included in this database as occupational SARS-CoV-2 infections are directly managed within the Occupational Health and Safety services departments in the hospitals of the national health system. Furthermore, the sector identified with the International Standard Industrial Classification of All Economic Activities (ISIC) code "O", i.e. Public administration and defense activities, including military and police personnel, is not included in the present analysis, as almost all the personnel of the Public administration services was smart-working during the months of the lock-down in Italy (March-June), and in any case direct contacts with the public were forbidden. Military and police personnel are not included in our registry, as they have, like HCW, specific internal procedures within their institutions for the management of the cases of infections. Also workers of the education system were not included as schools were closed in Italy during the lock-down in the period March-June 2020, and then for the Summer break. Finally, another category of workers not included in the present analysis is that of the domestic services (e.g. cleaning services), as in Italy they are usually employed directly as families' collaborators, so that they were not included in the companies' screening campaign.

Excluding these above-mentioned occupational sectors, we considered the total number of workers active in the province of Modena, consulting the database of the local department of the National Institute for Insurance against Accidents at Work (INAIL), updated to the year 2018 [8], and of the Chamber of Commerce [9] (this latter consultation was needed in particular for data on workers occupied in Agriculture, as these workers are included in separate lists for INAIL, and the full data on the number of occupied was not available on the INAIL database), and we calculated the percentage distribution of the workers according to the ISIC sectors [10]. Then, among the workers with serological anti-SARS-CoV-2 positivity, we calculated the distributions of the subjects according to the same ISIC working sectors, and we evaluated the differences. 


\section{Results}

According to INAIL, in Modena province 264.730 insured workers are employed [8]. Excluding healthcare workers and the other groups of workers not involved in the present analysis (i.e. from the education, domestic service, public administration and police/military sectors), and including further workers from the agricultural sector [9], it can be estimated a remaining working population of 246608 workers. 371 cases of serological anti-SARS-CoV-2 positivity in workers have been notified to the section of Occupational Health and Safety of the local Department of Public Health through the screening campaigns performed in the companies of the province of Modena, while other 732 cases have been reported by the General Practitioners, for a total of 1103 cases, representing the $0.45 \%$ of the non-healthcare working population of the province. Of these cases, the $34.6 \%$ tested positive for both IgM and IgG anti-SARS-CoV-2, while the $50.6 \%$ only for IgG and the $14.8 \%$ only for IgM. Of the 1103 subjects only 34 , the $3.1 \%$ of the total, resulted with a positivity also to the RT-PCR nasopharyngeal swab, being therefore diagnosed with a SARS-CoV-2 asymptomatic infection.

In order to evaluate the working sectors involved, as stated in the Methods section, we had sufficient information only for the 371 cases notified through the private companies serological screening. As incomplete data were available for 38 workers, the total sample for further analysis is composed of 333 individuals. The distribution of anti-SARS-CoV-2 positivity in the different working activities was: $59.8 \%$ in the manufacture activities (ISIC section C), $11.7 \%$ in the wholesale and retail trade sectors (ISIC section G), 8.7\% in the Transportation and storage sector (ISIC section H), 4.8\% in Professional, scientific and technical activities (ISIC section M), 4.5\% in the Arts, entertainment and recreation activities (ISIC section R) and the $10.5 \%$ in the remaining working activities. For comparison, of the 246608 non-healthcare workers of the province of Modena, the $43.6 \%$ are employed in manufacture, the $13.6 \%$ in the trade sector, the $4.1 \%$ in transport, the $3.7 \%$ in scientific and technical activities, the $0.6 \%$ in arts and recreation activities (Table 1).

Table 1. Distribution of the non-Health Care working population in the province of Modena and distribution of non-Health Care Workers with anti-SARS-CoV-2 antibody positivity in the same province according to the occupational sectors classified with ISIC codes.

$\begin{array}{cc}\text { Total number of workers } & \begin{array}{c}\text { Distribution of the } \\ \text { workers in the group of } \\ \text { employed in Modena } \\ \text { the } 333 \text { with positivity } \\ \text { province: } \% \text { (n) }\end{array} \\ & \text { for antibodies an- } \\ & \text { ti-SARS-Cov-2: } \% \text { (n) }\end{array}$

Distribution of the workers in the group of

\section{ISIC category ${ }^{1}$}
A. Agriculture, forestry and fishing
B. Mining and quarrying
C. Manufacturing
D. Electricity, gas, steam and air conditioning supply
E. Water supply; sewerage, waste management and remediation activities
F. Construction
G. Wholesale and retail trade; repair of motor vehicles and motorcycles

$2.8(6908)$
$0.1(314)$
$43.6(107434)$
$0.3(727)$
$0.4(891)$
$9.4(23077)$
$13.6(33533)$
$4.1(10227)$
$4.0(9931)$ 0 0 $59.8(199)$ 0 0
H. Transportation and storage 4.0 (9931)
I. Accommodation and food 
service activities

J. Information and communication

$2.4(5856)$

5.7 (14096)

0.9 (2197)

3.7 (9230)

$2.3(5675)$

$0.6(1486)$

$2.3(5701)$

0

$3.8(9325)$

$100(246608)$
0

$1.2(4)$

0

$4.8(16)$

${ }^{1}$ Occupational activities not included in the present analysis (number of workers employed in Modena province): O. Public administration and defense; compulsory social security ( $\mathrm{n}=6017)$; $\mathrm{P}$. Education ( $\mathrm{n}=2457)$; Q. Human health and social work activities ( $\mathrm{n}=15987)$, T. Activities of households as employers; undifferentiated goods- and services-producing activities of households for own use $(\mathrm{n}=29)$.

\section{Discussion and Conclusions}

Our results show a quite low frequency $(0.45 \%)$ of anti-SARS-CoV-2 antibodies positivity in a period of about five months in a working population of a northern area of Italy, one of the most afflicted by the pandemic during its first wave. These data certainly underestimate the effective diffusion as, first of all, the group of anti-SARS-CoV-2 positive non-HCW notified to the Section of Occupational Health and Safety of the local Department of Public Health of Modena refers to a negative population which is actually not that of all the non-HCW of the province, i.e. the denominator we choose to estimate the frequency, but only that of the total number of serological tests performed in the working population in the province in the period we examined (a data that unfortunately was not available, as it can be obtained only consulting all the private labs that performed the tests in the province), most likely only a percentage of this number. Recent Italian data indicated a prevalence of anti-SARS-Cov-2 IgG positivity in Emilia-Romagna region equal to the $2.8 \%$, with no difference between occupied and unoccupied subjects, and registered in a period of about two months [11]. According to this data and considering the number of non-HCW in our province and the longer period monitored, we should have expected a number of SARS-CoV-2 positivity about ten-times higher, and this indicates that the percentage of workers screened is most likely around the $10 \%$ of the total number of non-HCW. Accordingly, the real frequency of workers who probably had a contact, whether symptomatic or asymptomatic, with the new coronavirus in our province in a period of five months can reach the $5 \%$ of all the active non-HCW. This percentage is coherent with the Italian data $[4-5,11]$, considering the exclusion of HCW from our analysis, and the fact that active workers have a mean age significantly lower compared to that of the general population, and, most important, that during the period March-June 2020 many of the occupational sectors that we analyzed experienced severe restrictions of their activities, due to the national lock-down [5].

Considering the abovementioned limits, in any case our data shows some differences in the distribution of anti-SARS-COV-2 positivity rates among the non-healthcare working population of an Italian province, Modena, highly industrialized and included in an area of the nation, northern Italy, deeply impacted by the COVID-19 outbreak. In 
particular, we report higher rates of anti-SARS-COV-2 antibodies positivity in the manufacture, transportation and art/recreational (including sport) sectors, when comparing the distribution of the cases with that of the working population in the same territory.

As a conclusion, we can affirm that our data, to be interpreted with caution for the limitation of our analysis, indicates a possible higher rate of anti-SARS-CoV-2 antibodies positivity in the workers of the manufacture and transportation sectors, that were typically the activities that remained opened, also during the Italian national lock-down, for almost all the period. Moreover, it is interesting the data related to arts and recreational activities, including sports, where we found an anti-SARS-CoV-2 positivity rate about eight times higher compared to the proportion of workers employed in this sector in the province.

Author Contributions: Conceptualization, F.G., D.F., M.V., P.B., and A.B.; methodology, F.G. and A.M.; formal analysis, T.M., A.M.; investigation, T.M., A.M., N.B., T.F., S.P. and I.M; writing-original draft preparation, A.M., T.M., and F.G.; writing-review and editing, N.B., T.F., S.P., I.M., D.F., M.V., P.B. and A.B. All authors have read and agreed to the published version of the manuscript.

Funding: This research received no external funding.

Institutional Review Board Statement: The study was conducted according to the guidelines of the Declaration of Helsinki, and approved by the Ethics Committee of the "Area Vasta Emilia Nord" (protocol code 776/2020/SPER/UNIMO SIRER ID 540 of the 11 ${ }^{\text {th }}$ September 2020).

Informed Consent Statement: Patient consent was waived as the results presented in the article are related to a retrospective analysis of anonymous data.

Conflicts of Interest: The authors declare no conflict of interest.

\section{References}

1. Gobba, F.; Dall'Olio, E.; Modenese, A.; De Maria, M.; Campi, L.; Cavallini, G.M. Work-Related Eye Injuries: A Relevant Health Problem. Main Epidemiological Data from a Highly-Industrialized Area of Northern Italy. Int J Environ Res Public Health 2017 , 14(6), 604. doi: 10.3390/ijerph14060604.

2. Gómez-Ochoa, S.A.; Franco, O.H.; Rojas, L.Z.; Raguindin, P.F.; Roa-Díaz, Z.M.; Wyssmann, B.M.; Guevara, S.L.R.; Echeverría, L.E.; Glisic, M.; Muka, T. COVID-19 in Healthcare Workers: A Living Systematic Review and Meta-analysis of Prevalence, Risk Factors, Clinical Characteristics, and Outcomes. Am J Epidemiol 2020, kwaa191. doi: 10.1093/aje/kwaa191. Epub ahead of print.

3. Sim, M.R. The COVID-19 pandemic: major risks to healthcare and other workers on the front line. Occup Environ Med 2020 , 77(5), 281-282. doi: 10.1136/oemed-2020-106567.

4. Epidemiology for public health - Istituto Superiore di Sanità. COVID-19 integrated surveillance data in Italy. Available online: https://www.epicentro.iss.it/en/coronavirus/sars-cov-2-dashboard (accessed on 4th January 2021)

5. Marinaccio, A.; Boccuni, F.; Rondinone, B.M.; Brusco, A.; D'Amario, S.; Iavicoli, S. Occupational factors in the COVID-19 pandemic in Italy: compensation claims applications support establishing an occupational surveillance system. Occup Environ Med 2020, 77(12), 818-821. doi: 10.1136/oemed-2020-106844.

6. European Centre for Disease Prevention and Control. COVID-19 clusters and outbreaks in occupational settings in the EU/EEA and the UK. Available online: https://www.ecdc.europa.eu/en/publications-data/covid-19-clusters-and-outbreaks-occupational-settings-eueea-and-uk (accessed on 4th January 2021)

7. Dyal, J.W.; Grant, M.P.; Broadwater, K.; Bjork, A.; Waltenburg, M.A.; Gibbins, J.D.; Hale, C.; Silver, M.; Fischer, M.; Steinberg, J.; Basler, C.A.; Jacobs, J.R.; Kennedy, E.D.; Tomasi, S.; Trout, D.; Hornsby-Myers, J.; Oussayef, N.L.; Delaney, L.J.; Patel, K.; Shetty, V.; Kline, K.E.; Schroeder, B.; Herlihy, R.K.; House, J.; Jervis, R.; Clayton, J.L.; Ortbahn, D.; Austin, C.; Berl, E.; Moore, Z.; Buss, B.F.; Stover, D.; Westergaard, R.; Pray, I.; DeBolt, M.; Person, A.; Gabel, J.; Kittle, T.S.; Hendren, P.; Rhea, C.; Holsinger, C.; Dunn, J.; Turabelidze, G.; Ahmed, F.S.; deFijter, S.; Pedati, C.S.; Rattay, K.; Smith, E.E.; Luna-Pinto, C.; Cooley, L.A.; Saydah, S.; Preacely, N.D.; Maddox, R.A.; Lundeen, E.; Goodwin, B.; Karpathy, S.E.; Griffing, S.; Jenkins, M.M.; Lowry, G.; Schwarz, R.D.; Yoder, J.; Peacock, G.; Walke, H.T.; Rose, D.A.; Honein, M.A. COVID-19 Among Workers in Meat and Poultry Processing Facilities - 19 States; April 2020. MMWR Morb Mortal Wkly Rep 2020, 8, 69(18). doi: 10.15585/mmwr.mm6918e3. 
8. Banca Dati Statistica INAIL. Aziende e Lavoratori - Industria e Servizi - Quadro Generale. Available online: https://bancadaticsa.inail.it/bancadaticsa/bancastatistica.asp?cod=0 (accessed on 4th January 2021)

9. Camera di Commercio di Modena. Occupazione: si fanno più evidenti gli effetti della pandemia. Available online: https://www.mo.camcom.it/informazione-economica/informazione-economica/news/occupazione-si-fanno-piu-evidenti-gli-ef fetti-della-pandemia (accessed on 4th January 2021)

10. The International Standard Industrial Classification of All Economic Activities (ISIC). Available online: https://unstats.un.org/unsd/publication/seriesm/seriesm_4rev4e.pdf (accessed on 4th January 2021)

11. ISTAT. Primi risultati dell'indagine di sieroprevalenza sul SARS-CoV-2. Available online: https://www.istat.it/it/files//2020/08/ReportPrimiRisultatiIndagineSiero.pdf (accessed on 4th January 2021) 